\title{
Building a Viable Flight Risk Assessment Process in Business Jet Operations: Selecting a Risk Assessment Tool, Setting Baselines, Trigger \& Mitigation Points
}

\author{
Cory D. Chamberlain \\ Utah Valley University
}

\begin{abstract}
In November 2006, The International Civil Aeronautics Organization (ICAO) issued a mandate for all member nations to set a state standard for all aviation service companies to have integrated safety management systems (SMS) in place by 2009. The FAA issued an advisory circular (AC120-92A) in 2010 addressing this issue. To date SMS has not been mandated in the United States. A major part of any SMS is creating a process for assessing risk. This paper is a case study of how one jet charter company selected a flight risk assessment tool (FRAT), trained their pilots and then analyzed close to 800 flights in order to set trigger points for assessment use, risk values that required management involvement, and risk values that required some sort of mitigation. The paper also discusses how the operation dealt with pilot push back, FRAT evolution and the dynamic personality of aviation in general.
\end{abstract}

\section{Introduction}

In November 2006, The International Civil Aeronautics Organization (ICAO) issued a mandate for "all member nations to set a state standard for all aviation service companies to have integrated safety management systems (SMS) in place by 2009" (p. 1). The Federal Aviation Administration (FAA) issued an advisory circular (AC120-92A) in 2010 addressing this issue. The focus of the FAA shifted elsewhere after the fallout from the Colgan Air Disaster in Buffalo, New York, however; hence, to date there has not been an SMS mandate issued in the United States. According to most industry sources an FAA mandate is still inevitable (Allen, 2011). Further SMS integration is also occurring in fields as diverse as academia and heavy industry as entities such as the Occupational Safety and Health Administration (OSHA) and the Aviation Accrediting Board International (AABI) are both considering implementing an SMS requirement (AABI, 2013; OSHA, 2013).

ICAO Annex 6, Appendix 1 describes the "framework," which is the standard for a "robust” SMS program (FAA, 2011). The “components, elements and processes” spelled out are mirrored by the FAA advisory circular as well as third party groups such as the International Business Aviation Council (IBAC) and the Air Charter Safety Foundation (ACSF) (ASCF, 2013; IBAC, 2013; FAA, 2010). The FAA is taking the stance that they will mandate "what" an organization does rather than "how" they do it. The framework consists of four components, or "pillars" as the ACSF likes to call them. These pillars are Safety Policy, Safety Risk Management, Safety Assurance and Safety Promotion. Each pillar is further delineated into elements, which contain processes. This article will deal 
primarily with the Safety Risk Management component, and more specifically the Risk Assessment process contained in the Safety Risk Management component.

\section{Risk Assessment}

Most safety professionals are familiar with the elements involved in a good risk assessment process. Basically, any valid risk assessment should take into account the severity of an occurrence balanced by the probability that the occurrence will actually happen (FAA, 2009, p. 4-2). Many risk assessments will appear in a matrix form similar to Figure 1.

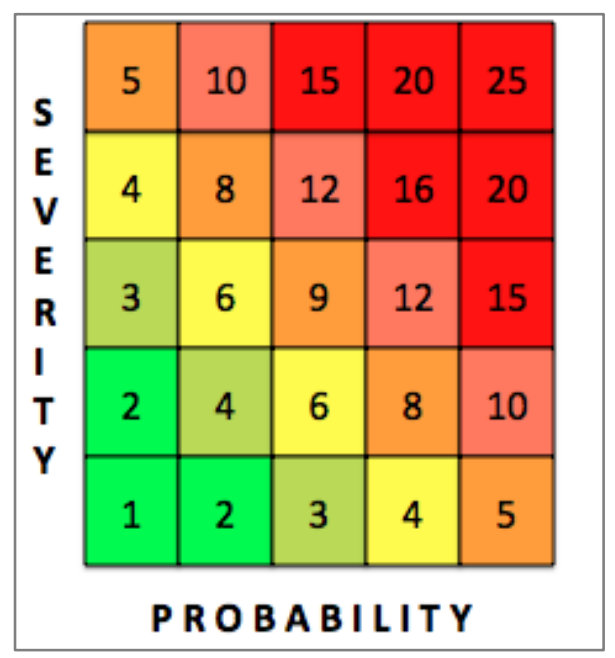

Figure 1. Risk Assessment Matrix Depicts Probability vs. Severity adapted from FAA Matrix (FAA, 2008).

The matrix demonstrates that factors that need the most attention are the ones that have both a severe outcome (i.e. death or heavy monetary loss) and a high probability of occurrence. Risk values or scores will go down from there as the predicted severity and probability of occurrence go down.

The National Transportation Safety Board (NTSB) considers any occurrence in an aircraft, once people are aboard, which involves a death or substantial aircraft damage to be an aircraft accident (NTSB, 2011, p.1). Some agencies, for instance the state of Indiana, take it one step further and require an accident report for losses as low as 100 dollars (Office of Code Revision Indiana Legislative Services Agency 2013). With the current cost of jet aircraft, even the simplest of incidents can easily exceed this particular threshold. With this information in mind, it is understandable why most flight risk assessment tools (FRATs) only require assessors to place a value on the probability side of the matrix; the severity side is pretty much a given. 


\section{Mission}

Early in 2008, the author of this article was tasked with developing a flight risk assessment process for a medium-sized jet operator in the intermountain west. Mediumsized refers to the fact that at the time they operated four Gulfstream jets, two Hawkers, two Citations, one Challenger and three Pilatus aircraft. The company did quite a bit of supplemental lift for the fractional carriers and brokers. These entities required annual safety audits, so this operator already had a fairly robust SMS in place. The issue was the level of the system. A good flight risk assessment process is important to any flight operation's safety management system and for that reason the operator also had a FRAT in place that had been provided by one of their ex-military pilots. He had used the FRAT in the US Air Force and the company was grateful for the help. It wasn't a bad FRAT; the problem was that it was cumbersome at best. It was three pages long and asked for quite a bit of subjective data, it had questions that meant different things to different people, along the lines of illness, stress and fatigue. These are great for determining personal airworthiness, but we were looking for consistency. The FRAT filled the checklist box. Whenever an auditor came by, management could show them the tool. If the auditor asked a pilot about it, he or she may have been able to find a copy, even fill it out, but had no idea what the numbers meant once completed. After all, it is one thing to have a FRAT that lives in a drawer so you can prove to an auditor that it exists, but it is quite another to be able to show an auditor that all of the pilots and dispatchers have been trained to use it (and show competence), to be able to demonstrate the average risk value for a summer or winter flight, and to understand at which particular risk value management involvement is required and at which value the pilots need to mitigate risk.

What follows in this article is a five-year case study of how this medium sized jet operator developed and implemented a flight risk assessment process into everyday operation. Included is a report on the findings of a study of over 700 flights and how the operator used this information to set baseline risk values for the department. Though this information was never meant to be a hard scientific study, it represents a logical way to figure out where to set thresholds. Therefore, the study is not perfect but it represents a much better system than simply setting arbitrary limits based on nothing but a guess. Following a description of the study will be a discussion of some of the pushback received from the pilot group, how buy-in from that group was achieved, how the entire process was allowed to evolve through continued additions to the database, how "use triggers" or "trigger points" were developed and at what point management required risk mitigation ("mitigation points"). Finally, a discussion of what went right, and what went wrong from an implementation point of view will be presented and how new options currently available may be applied for those presently developing a risk assessment process. 


\section{Method}

In this section we will discuss how a team of managers worked together to select a suitable FRAT and then how data collected from its use was analyzed in order to set the aforementioned mitigation points.

\section{The Team}

The "Safety Team" consisted of management for this particular mountain west operator. It was made up of the Director of Operations, Assistant Director of Operations, the Director of Standards, the Flight Safety Officer and included input from the Director of Safety, the Chief Executive Officer and Chief Pilot. Meetings were held as needed, usually on a biweekly basis so assignments could be given and those completed could be reported on. The biweekly meeting was also the time most decisions were made. The first assignment was to decide on which new FRAT to use from the myriad available, and then

decide how to implement it. Prior to selection, however, the team set some basic goals for the tool and they are as follows:

1. It needed to be objective. The risks factors listed needed to be easily identified. More specifically, the risk factors needed to be described in a way that made it easy for pilots to determine if they were present or not. The goal was that 10 pilots would come up with 10 identical total risk values/scores for any given flight.

2. It needed to be practical. Pilots have a lot of paperwork. The pilot group simply wouldn't use a FRAT that took 25 minutes to fill out. A good FRAT would be a one- page document or electronic form that took in human, environmental and mechanical factors.

3. Risk factors needed to be at least loosely based on accident statistics. It needed to consider the severity/probability matrix previously mentioned. A FRAT based on accident stats would add the probability side to the matrix.

\section{The Instrument}

The team found numerous instruments related to the study topic. There were several FRATs readily available, but the one chosen came straight from the FAA. It was issued in a FAA "InFo" and was developed by the Turbine Aircraft Operations Subgroup as part of the General Aviation Joint Steering Committee. The Subgroup had reviewed accident data to come up with risk factors and the initial "risk values" associated with each factor (FAA, 2007, pp. 1-5). This tool was just what management was looking for. The form itself was divided into three sections: one for the flight crew, one for the environment, and one for mechanical/maintenance. Completing this particular FRAT was easy for crews. Each factor was already scored so that all a crew needed to do was determine if a 
factor was present. If a factor was present, the pilot simply wrote the risk value indicated by the designers into the column on the right. When finished, the crew added up the totals. It met all three of the original goals and was easily adaptable (See Appendix 1). The next step was implementation and a study to determine company baselines.

\section{Training and Implementation}

Once a FRAT was selected, initial implementation was fairly straightforward. Management simply had to define the procedure and then train those employees involved. The managers understood that before they could determine when risk mitigation needed to take place (changing something to reduce risk), they first needed to determine what risk values were "normal" for the operation. To figure out what was "normal," enough data needed to be collected, or in this case enough risk assessments completed and tracked to see what the overall average for a flight was for this particular organization. Options were discussed in several safety management meetings and as a general rule all were in agreement that the best way to come up with an average was to have the pilot group complete risk assessments for every flight they completed. The only dissenter was the company's Flight Standards Officer. The standards officer was fine with mandating the completion of flight risk assessments every flight, just not indefinitely. He wanted a definite sunset date since he believed that the pilots were already required to complete too much paperwork, manifests, weight and balance, engine monitoring, and at the time, reduced vertical separation (RVSM) logs. He believed that if risk assessments were required before every flight on a continuous basis, assessments would become just another task pilots needed to complete. This in turn would severely threaten "buy in" by the pilot group. His opinion was fairly prophetic and will be discussed later in the article. After much discussion, management decided that risk assessments would be collected for three months in the summer and three months in the winter. This timeframe was chosen basically to follow the seasons in which the FAA requires recurrent training. Pilots and dispatchers were trained in the use of the FRAT during recurrent training in the months leading up to process implementation.

\section{Procedure}

At the time for implementation, all of the pilots and crew schedulers had been fully trained. The process was straightforward. Crew schedulers placed an adequate number of forms for each leg of a trip into the trip packets. Once a trip was completed, the trip packets with the fuel receipts, etc. were turned into the accounting department. The safety team placed a file in the accounting office so that as the trip packets were checked and filed, the completed risk assessments could be collected and placed in the file.

\section{Results}

Completed risk assessments were collected for all flights between May $15^{\mathrm{t}}$ and September $31^{\text {st }}$, 2008 and then again for all flights between December 15 and March 31, 
2009. The data from each assessment were then entered into a "Filemaker Pro" database program and compiled electronically. In all, there were 734 assessments entered. Specifically, there were 433 collected during the summer months and 301 during the winter. The overall average risk value for a flight at this operation was 13.06 points. Summer flights had an average risk value of 11.64 while the winter flights averaged 15.16. There were more summer flights than winter. If the seasons were equally weighted, the average risk value per flight was 13.40. At that time, the most frequently indicated risk factors were "Captain \& FO less than 100 hours in last 90 days." The least frequently indicated risk factors, averaging well less than .1 point per flight, were those dealing with mechanical issues (see Figure 2). Appendix 1 is a sample of the FRAT showing details of each risk factor. Although "crew qualification and experience" issues had the most frequency, the "operating environment" category contributed the most to the average risk score. This was due to the fact that the crew qual. category (as it appears in figure 2) had eight separate factors compared to twenty-seven in the environment category.

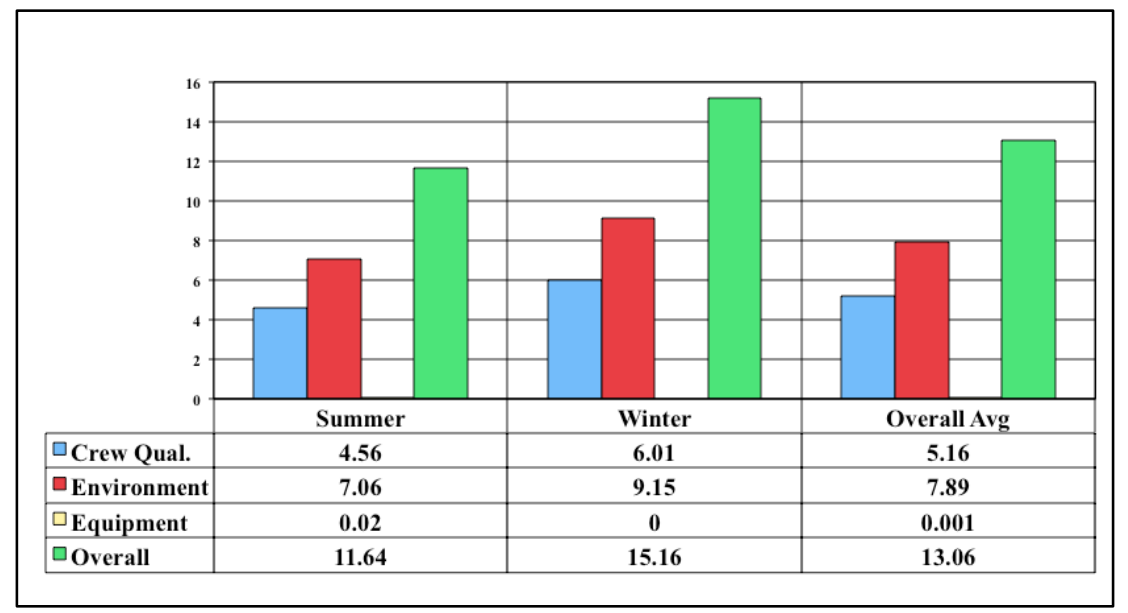

Figure 2. Average Risk Value Totals by Category. Depicts Average Scores by Category. This chart shows the average totals of each of the three general categories; Crew Qualification and Experience, Operating Environment and Equipment for Summer, Winter and overall.

All data were entered into an IBM SPSS stats program and the following descriptive statistics were the result: Mean total risk value per flight: 13.08, Mode 24.00, Standard Deviation: 7.47. The stats program rounded slightly differently than the Filemaker Pro program, hence the .02 point difference in the mean (see figure 3 ). 


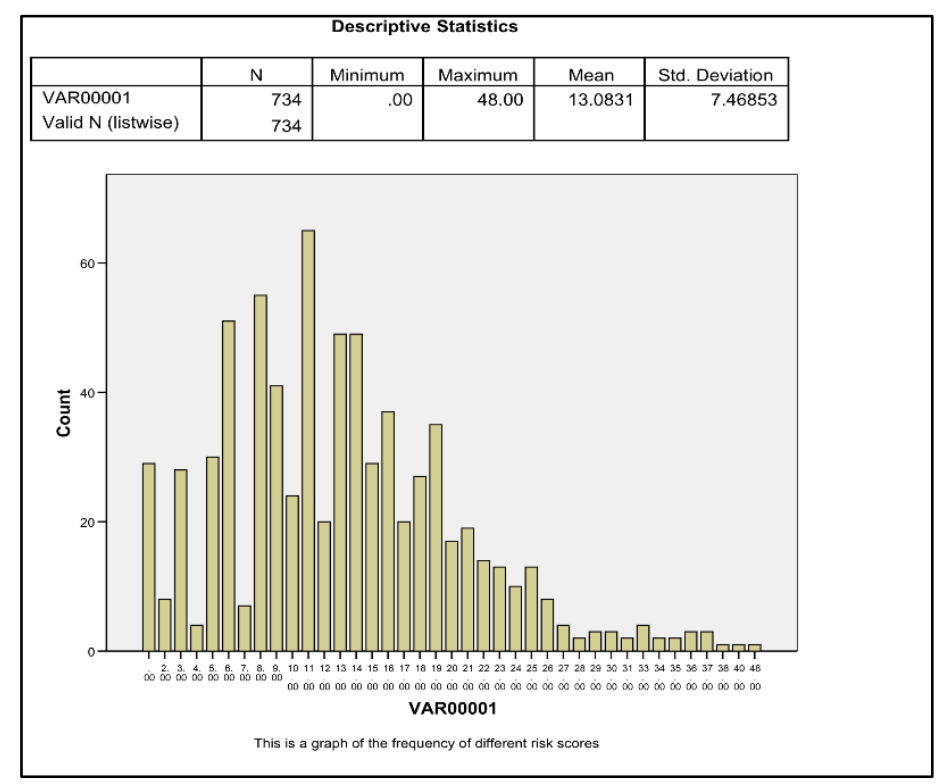

Figure 3. Descriptive Statistics and Frequency of Different Risk Factors Present. This figure shows how often a particular risk factor was indicated present by a pilot. At the top, it shows the mean, minimum, maximum and standard deviation of total risk values entered per flight. (Output from IBM SPSS software.)

The next task was to decide what to do with the information collected and set usable baselines, triggers and mitigation points.

\section{Setting Baselines and Mitigation Points}

The point of determining an operational risk value average for the flight operation was to make it easier for management to decide when they should get involved in the flight decision process and at what point a trip should be turned down or modified. During the meetings that ensued on the subject, one highly experienced manager expressed that he had noticed that in many accident reports that it seemed that it was the addition of "one more thing" that turned the flight into an accident. He suggested that management involvement should occur at a risk value equal to one risk factor with a large score. For example, flights around thunderstorms will increase the total risk value of a flight by 5 points. He suggested that the threshold for management involvement be determined by adding five points to the operational "baseline" risk. This suggestion was much to the chagrin of the Flight Safety Officer (who had spent all night entering risk assessments into an IBM student version of the Statistical Package for Social Sciences [SPSS] stats package). His five-point rule was within a point or two of the standard deviation. Looking at the graph of the data, it is not exactly a bell curve. There were quite a few outliers on the high end of the scale. By using the standard deviation based on the mean around thirteen points, the limits would be fairly conservative and any flights with the higher risk values would automatically require management involvement. The safety management 
team eventually agreed to a "management involvement" threshold risk value determined by adding a rounded version of the standard deviation to the company average total risk value.

The "mitigation point" or risk value where some kind of change should occur (different airport, extra crew, reposition the night before, etc.) was slightly more complicated to figure out. International flights came with much higher risks and setting an arbitrary point where something had to change could prove to be a nuisance, the company could lose flights, or worse, if too cumbersome could encourage pilots to ignore the procedure. It was decided that since any flight with a score above 22 needed management oversight anyway, the mitigation point could be set high enough to accommodate international risk values. Figure 4 describes the two risk value thresholds and is identical to the way they were presented to the pilots and crew schedulers. This chart depicts the risk values above which some kind of action is required on the part of management and the crew. This chart was included in all training and on the back of every FRAT form.

\section{Trigger Points}

One of the best decisions management made concerning the flight risk assessment process was not all that intuitive, at least not at first. As mentioned earlier, part of the management team was very much against requiring crews to fill out risk assessments for every flight except for the time frame of the initial baseline tests. For reasons already explained in the "training and implementation" section, he thought it would ruin the intent

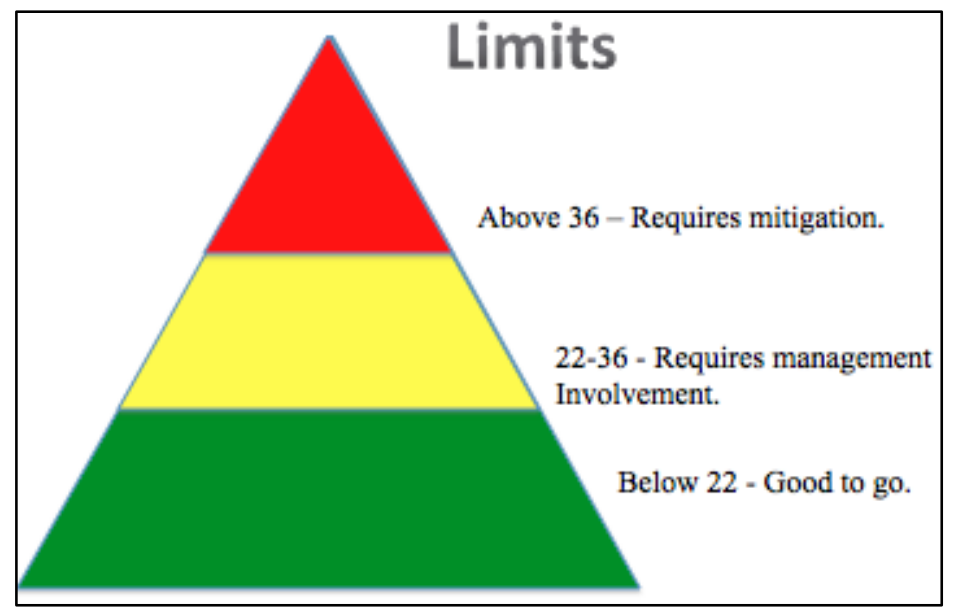

Figure 4. Shows Risk Value Thresholds that require management involvement in the go/no decision (scores between 22 and 36) or risk mitigation (scores above 36). This was 
developed in house borrowing the shape and colors from the Heinrich Pyramid (Heinrich, 1941).

of the entire process. He was correct, at least in one operation. The safety team's Flight Safety Officer (FSO) attended a safety symposium at the Air Charter Safety Foundation's (ACSF) headquarters co-located with the National Transportation Safety Board (NTSB) in Washington D.C. He relayed a story that took place in one of the discussions at a reception for flight safety officers and managers from across the United States. One FSO explained how it was almost embarrassing for her. Her company required crews to complete flight risk assessments for every flight. She said crews wouldn't even hide the fact from her that they were completing the risk assessments at the end of the trip simply so they had something to turn in. This was definitely not the case for the operation we are discussing, but that is because well-defined trigger points were set. After deciding when to mitigate risks, management went about deciding when a flight risk assessment completion was required. Again, in a safety management meeting the issue was well discussed. The group was in unanimous agreement on mandating risk assessments for "pop-up trips" (less than four hours notice), international trips, single pilot trips, and anytime someone had a gut feeling factors were adding up. After much discussion, they also decided to mandate completion for trips that occur outside of normal circadian highs, training flights (to check competency), and anytime the "rule of three" (three factors added up: a tired pilot, bad weather, and a maintenance item, for example) occurred. The process was re-visited several times and after a couple years of implementation it was also decided to require risk assessments to be completed for maintenance check and ferry flights and for any flight that was carrying a maintenance item that required a limitation such as "Day VFR." The team also came up with suggestions about who could generate or cause the generation of a flight risk assessment.

After 5 years, the process has reached the point that long-time customers are even asking about the risk values for the flights where they are passengers. Below is a list of the "trigger points" that have evolved over the five-year implementation. These are also listed in the company's Standard Operating Procedures (SOP) and on the back of every FRAT form.

Risk Assessments must be completed for the following operations:

- Pop-up trip with less than 4 hours notice.

- Training flights and checkrides.

- Maintenance checks and maintenance ferry flights.

- MEL or CDL flights requiring Day VMC or non-standard aircraft flight configuration.

- Flight is conducted between the hours of 22:00 - 05:00

(During the circadian low) appropriate to the time zone you are adjusted to at the time.

- $\quad$ Rule of three occurs. 


\section{Other conditions appropriate for the completion of a risk assessment include, but are not limited to:}

- Gut feeling

- Interest (idea that things may be stacking up).

- Concern from another crewmember, flight coordinator, operational management

- Night operations into mountainous airports listed in the Mountain Airport Restriction Table

- International flights

- Duty day in excess of 12 hours

\section{Risk assessments may be generated by anyone:}

- Captain

- First Officer

- Flight Attendant

- Dispatcher

- Management

- Passenger

\section{Discussion}

The discussion section describes what changes have been made five years into the implementation, how the process has evolved and recommendations to those just beginning to build a process of their own.

\section{The Process Five Years In}

As with any new process, there was some reluctance by the pilot group early on--not because they disagreed with the process, but rather because they just wanted to understand certain aspects. The safety management team was very proactive in letting the pilots know the reasoning for why the process was put into place. The pilots just had questions about the FRAT itself. One question was, "If the weather forecast is such that we don't need an alternate legally, why do I have to add points for 'no alternate selected'?" We explained that the risk factors were based on looking back at accident statistics. Airports are closed sometimes for reasons other than weather and it is always safer to have a plan B, than not. Another question was, "I have a risk value of zero for this flight; does that mean my risk is zero?" Again, a little discussion of "added risk" helped that particular pilot understand what he was looking at. Overall, once pilots started to understand that the FRAT wasn't a task they "had" to do, but one that could help them, they started to buy into the process. When they realized that they could use the FRAT to 
back up a decision, it became engrained. What can upper management say about changes such as repositioning the night before to reduce their duty day, or landing at a bigger part 139 "air carrier" airport instead of the regional when you have objective data depicting the higher risk? Being able to put a number to the risk empowered the pilots and there was no way management could complain. See Appendix 2 for examples of risk assessments that were used to back up pilot decisions.

\section{Evolution}

Anyone involved with the aviation industry knows how dynamic it can be. Business jet flight operations continually gain and lose airframes as owners upgrade to newer or bigger jets. Pilots change assignments or upgrade to new equipment. The trick is to keep the risk baselines evolving to reflect the changes. The goal is to have numbers that reflect the current company, not just a snapshot of the company five years ago. One downside to only requiring risk assessment completion for trips that meet a certain criteria is that those flight risk assessments, as a general rule, will naturally have higher risk values. If you use the data from mandated assessments to update the database you will slowly skew the baselines towards a higher risk. To continue letting the database evolve and reflect an "average" risk value of the present company, it was decided to randomly select flights for mandatory risk assessment completion. FRAT forms were printed in bright yellow and placed in the box with the other blank forms in the crew scheduling office. Each crew scheduler had a pair of dice and anytime they booked a flight, they rolled the dice. If the scheduler rolled a 7 or an 11 (22\% odds), one of the yellow forms was placed in the trip packet with a note telling the pilots for which leg they needed to complete an assessment. Pilots were alerted in a crew "must read" email which required response and again in a "safety news" update. It worked well, but as fun as the dice sounded, the procedure became pretty cumbersome for the schedulers and hard to remember on a busy day. In the end the crew schedulers just shuffled the packets at the end of every workday and picked every $5^{\text {th }}$ packet as a FRAT recipient. So far the baselines have only moved by a few decimals.

Another discovery over the long term was that some of the risk factors listed on the FRAT form were not ever indicated as being present, not even once. In evaluating the many completed risk assessments, the team found that two of the unused factors (Factor number 8 "crew rest" and number 22 "stopping distance") would be considered violations of the Federal Aviation Regulations (FARs) in some instances. They discovered that pilots, even if they were legal at the time, were not going to admit to exceeding limits that exist in other types of flying. In essence, some of the more restrictive FARS could be considered "best practice." For example, it is perfectly legal (albeit not all that smart) to exceed a 14-hour duty day when flying privately (FAR part 91); however, when flying on a charter flight under FAR part 135, it is not. Pilots never once admitted to the factor "Crew Rest (less than 10 hours prior to duty)" (CFR14, FAR 91, 135). Another risk factor with FAR-related issues concerned runway length. The factor was labeled as "stopping distance more than $80 \%$ of runway available.” Again, this condition is legal 
part 91 but not part 135, at least in the planning stage (CFR14, FAR 91, 135). The pilots once again avoided this factor completely. After much discussion within the safety management team, it was decided to simply modify the risk factors keeping the initial intent, but presenting the factor in a way that wouldn't require a pilot to admit to violating if not an FAR maybe best practice. The "rest" risk factor dealt with fatigue so the team changed it to "flight during night circadian low." The "stopping distance" factor was put in line with part 135 at $60 \%$. The changes made were not without precedent; when the FRAT was first implemented, for example, the Flight Safety Officer called one of the original developers of the tool (Peter Neff) primarily to ask if an operation that flies almost every other flight in the mountains necessarily needed to use the risk value listed. His advice was indispensable in helping the team understand how the FRAT could be tailored to a specific operation (Neff, 2008). The team eventually decided to leave the values alone and just accept a higher score, but five years in, the team is a little more versed in the process.

\section{Recommendations}

Six years after the FAA issued the original InFo containing the turbine operators FRAT, many more options for Flight Risk Assessment Tools are now available to those just developing their process. Automatic FRATs are now available in flight dispatch software packages, flight-planning websites, and as part of the services provided by large flight handlers (FOS, Universal, FltPlan/safety.com, 2013). These systems can greatly simplify the risk assessment process but as with any automation, situational awareness can suffer if not used correctly. The one advantage to using a manual FRAT is that when some form of mitigation is required, the risks can be easily identified because as you manually mark off whether or not a risk factor is present, you also identify them. This makes it easier to analyze and assess the factors that may need to be mitigated (FAA, 2007). This is not to say that risks can't be identified with an automatic FRAT; identification may not be as easy, however. The safety team has had several discussions about automatic FRATs; the recommendation they have for anyone using one is to pay attention to what the numbers tell you. Set your own baselines or benchmarks. When FltPlan.com tells you your risk score is a 14 for instance, pay attention to what a flight with a 14 score is like. Look at the details of the flight so you know what to mitigate when the score is high. Most of all, whatever process you use, make it your own and make it a system that you will use.

\section{Conclusion}

Flight risk assessment is a big part of any safety management system. A good process is one that is understood by those who use it, provides results that are easily interpreted, and most importantly, one that crews will use. This case study was not meant to be an allencompassing primer on flight risk assessment but simply an example of how one operator went about setting up a process. Over the five-year review, there were some

unintended consequences both in the good and bad categories, but that is half the fun in 
designing a process. Sometimes that is where people learn the most. In the end, if a flight department can design a process that pilots will use, that empowers them to back-up their decisions with objective data, and can evolve with the company, it can be considered a success. 


\section{References}

Air Charter Safety Foundation. (2013). SMS Overview [Brochure]. Retrieved from http://acsf.aero/sms/

Allen, J. M. (2011, March). Trends in aviation safety, challenges for 2011 and beyond. Your business plan for safety. Symposium conducted by the Air Charter Safety Foundation, Alexandria, VA.

Aviation Accrediting Board International. (2013). Accreditation criteria manual (proposed changes). Retrieved from http://www.aabi.aero/Forms\&Pubs/100BylawsRev03-05.pdf

Federal Aviation Administration. (2011). Safety Management System (SMS) “Read Me First” For: Safety Management System (SMS) Pilot Project Participants and Voluntary Implementation of Organization SMS Programs Revision 8, P.2. Retrieved from http:// www.faa.gov/about/initiatives/sms/...by.../sms_read_me_first.pdf

Federal Aviation Administration. (2010). Advisory Circular: Safety Management Systems for Aviation Service Providers (FAA Publication No. AC-120-92A). Retrieved from http://www.faa.gov/regulations_policies/advisory_circulars /index.cfm/go/document.information/documentID/319228

Federal Aviation Administration. (2009). Risk Management Handbook (FAA Publication No. FAA-H-8083-2). Retrieved from http://www .faa.gov/regulations_policies/handbooks

Federal Aviation Administration. (2008). Develop Preliminary Vulnerability and Risk Assessment (e). (Operations Website). Retrieved from http://www.faa.gov/about/office_org/headquarters_offices/ato/service_units/opera tions/isse/items/e-Dev-Prem-Vul-Risk-assessment.cfm

Federal Aviation Administration. (2007). Information for Operators: Flight Risk Assessment Tool (FAA Flight Standards Service Publication No. 07015 pp.1-5). Retrieved from http://www.faa.gov/other_visit/aviation_industry/airline_operators/airline_safety/i nfo/all_infos/

General Operating and Flight Rules, 14 Fed. Reg. Part 91. Federal Aviation Regulations. (2013). Retrieved from http://www .faa.gov/regulations_policies/faa_regulations/

Heinrich, H.W. (1941). Industrial Accident Prevention: A Scientific Approach. New York: McGraw-Hill. 
International Business Aviation Council. (2013). International Standard for Business Operations [Brochure]. Retrieved from http://www.ibac.org/safety

International Civil Aeronautics Organization. (2006). Annex 6: Operation of Aircraft, Part I - International Commercial Air Transport - Aeroplanes, and Part III International Operations - Helicopters. Retrieved from http://www.icao.int/safety/ism/ICAO Annexes/Annex 6.pdf

National Transportation Safety Board. (2011). Pilot/Operator Aircraft Accident/Incident Report (NTSB Form 6120.1 p.1) Retrieved from www.ntsb.gov/doclib/forms/6120

Office of Code Revision Indiana Legislative Services Agency. (2013). Aircraft Financial Responsibility Act (Report of Accidents Chapter 3, IC8-21-3-3). Retrieved from http://www.in.gov/legislative/ic/code/title8/ar21/ch3.html

Operating requirements: Commuter and On Demand Operations and Rules Governing Persons On Board Such Aircraft, 14 Fed. Reg. Part 135. Federal Aviation Regulations. (2013). Retrieved from http://www .faa.gov/regulations_policies/faa_regulations/

Rockwell Collins. (2013). Flight operations software: Control your operations with Ascend. Retrieved from http://www.flight-operations-software.com/ascend-fosmodules.html

The low cost and easy to use Safety Management System. (2013). Retrieved from Fltsafety.com website: https://www.fltsafety.com/SMSinfo.htm

United States Department of Labor, Occupational Safety and Health Administration. (2013). Process Safety Management of Highly Hazardous Chemicals; Explosives and Blasting Agents. Retrieved from http://www.osha.gov/pls/oshaweb/owadisp.show_document?p_table=PREAMBL ES\&p_id=1038

Universal Flight Support. (2013). Safety Management and Integration [Product Website]. Retrieved from http://www.universalweather.com/aviation-sms/software/ 


\section{Appendix 1}

\section{Flight Operations}

\section{Risk Assessment Process}

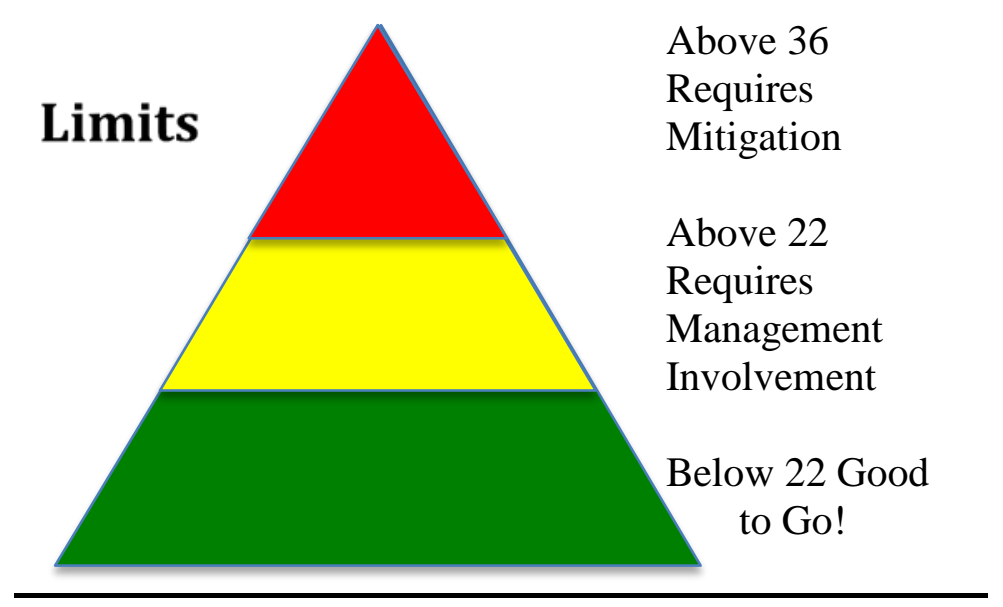

Risk Assessments must be completed for the following operations:

- Pop-up trip with less than 4 hours notice.

- Training flights and checkrides.

- Maintenance checks and maintenance ferry flights.

- MEL or CDL flights requiring Day VMC or non-standard aircraft flight configuration.

- Flight is conducted between the hours of 22:00 - 05:00 (during the circadian low) appropriate to the time zone you are adjusted to at the time.

- Rule of three occurs.

Other conditions appropriate for the completion of a risk assessment include, but are not limited to:

- Gut feeling

- Interest (idea that things may be stacking up).

- Concern from another crewmember, flight coordinator, operational management

- Night operations into mountainous airports listed in the Mountain Airport Restriction Table

- International flights

- Duty day in excess of 12 hours 
Risk assessments may be generated by anyone:

- Captain

- First Officer

- Flight Attendant

- Dispatcher

- Management

- Passenger

To complete a risk assessment, write the risk value for a particular risk factor present in the empty box to the right of the indicated value. Total up the risk values for each section then add section totals to determine the total risk factor score. 
Date:

Flight Risk Assessment Tool

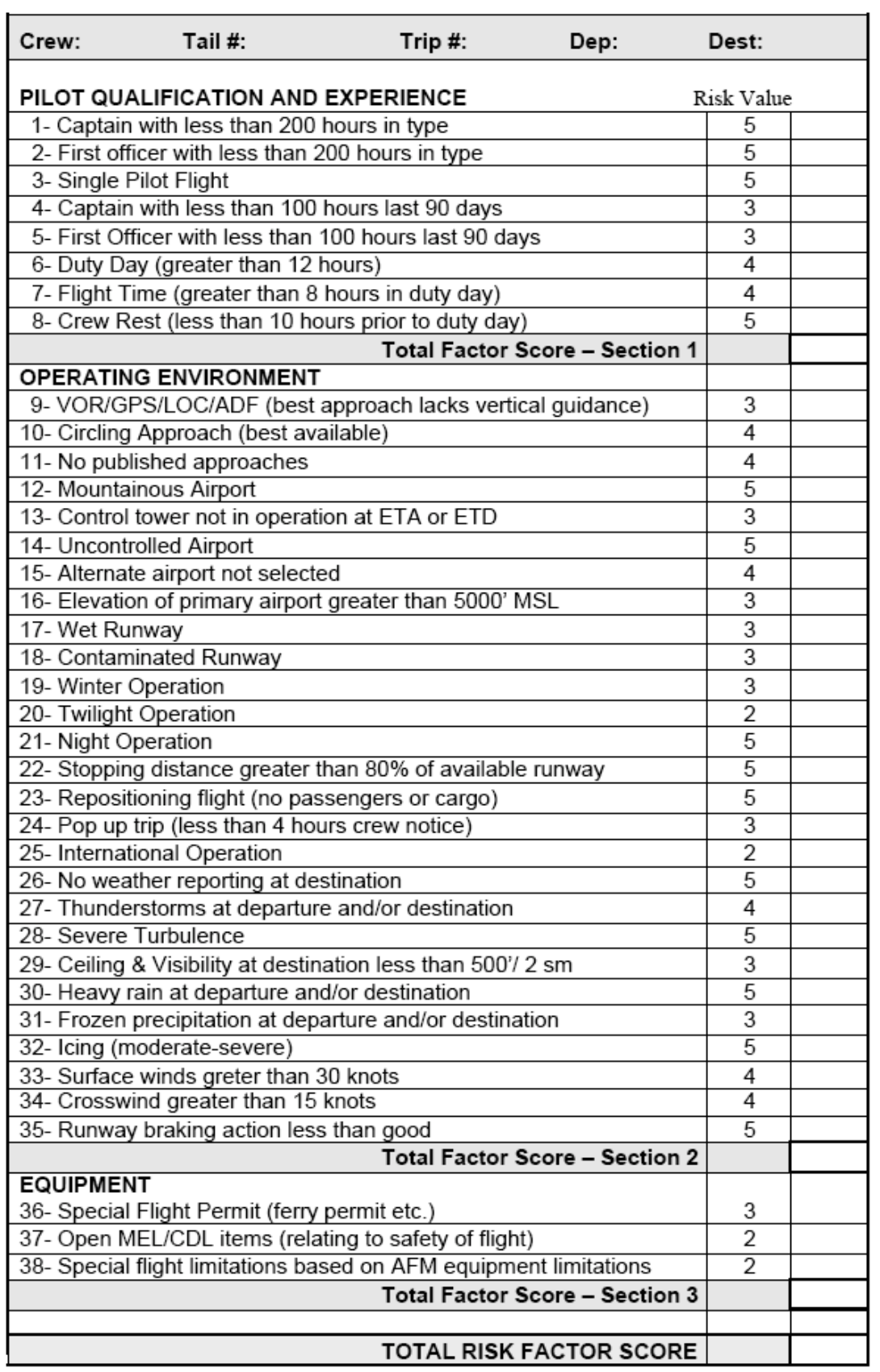




\section{Appendix 2}
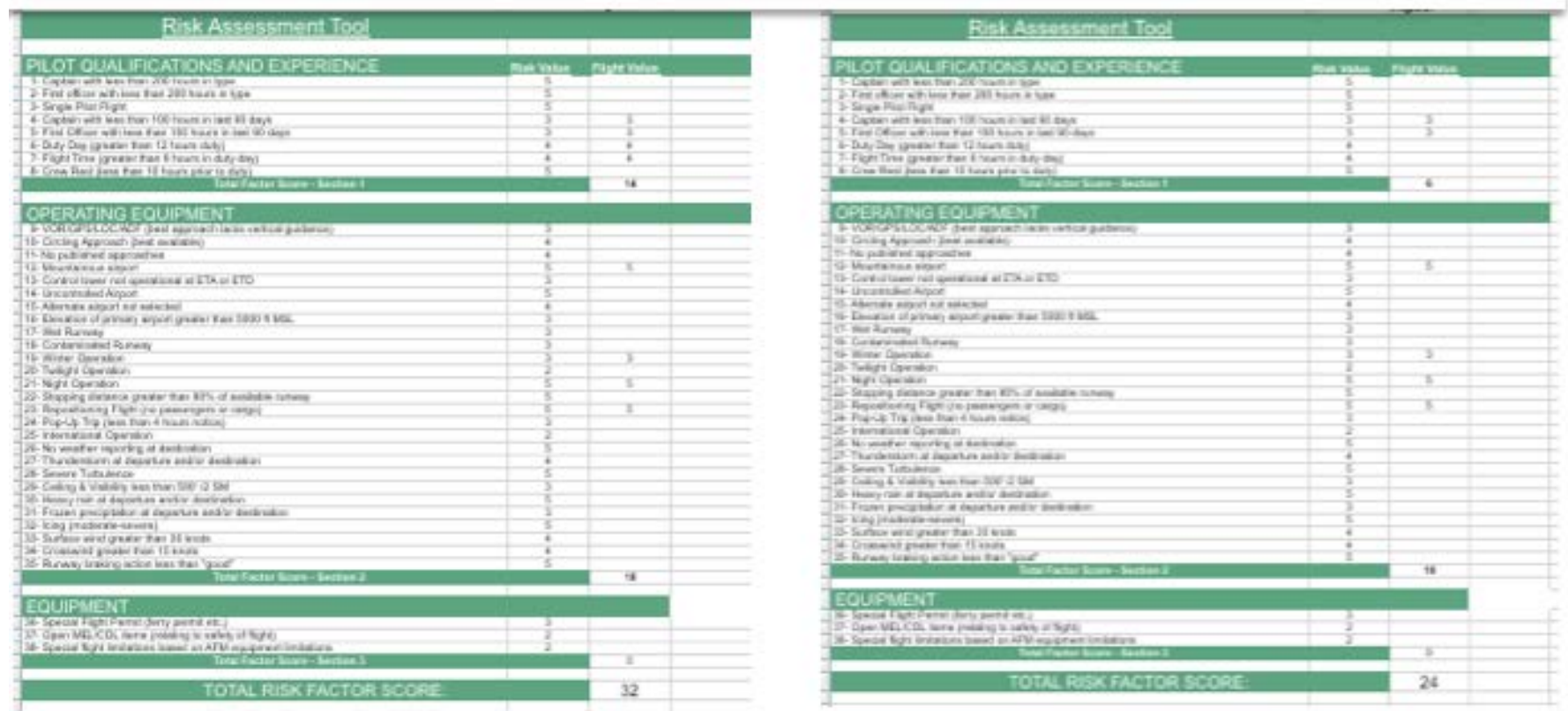

These two de-identified flight risk assessments show how one crew used the data from a planned trip with a long duty day to convince upper management to spring for the cost of a hotel room. The crew repositioned the night before reducing the risk value by 8 points. 